\title{
Clinical, brain imaging and therapeutic evaluation of toxoplasma encephalitis in HIV-infected patients in Yaounde
}

\author{
Annick Mélanie Magnerou*, V Sini, P Ongolo-zogo, JY Fonsah, AK Njamnshi, L Kaptue \\ From 17th International Symposium on HIV and Emerging Infectious Diseases (ISHEID) \\ Marseille, France. 23-25 May 2012
}

\section{Introduction}

Toxoplasma encephalitis is very common in patients with AIDS. The diagnosis is based mainly on the response to medical treatment.

\section{Objectives}

To evaluate clinical diagnosis, CT-scan findings, therapy and evolution of AIDS patients with toxoplasmic encephalitis.

\section{Material and methods}

It was a descriptive cohort study with a prospective and a retrospective phase. Neurologic deficit was scored by using the NIHSS (National Institute of Health Stroke Scale).

\section{Results}

Sixty consenting patients were recruited, the mean age was $38.7 \pm 9.7$ years. The $\mathrm{F} / \mathrm{M}$ sex ratio was 1.6. The mean CD4 cell was $53.5 \pm 42.6 / \mu \mathrm{l}$. The main presenting complaints were motor deficits (65\%), seizures (40\%), headaches $(31.7 \%)$, language and the speech disturbances $(35 \%)$. Signs of meningeal irritation and raised intracranial pressure were found in $21 \%$ and $10 \%$ of the cases respectively.

The brain lesions were all heterogeneous with contrast enhancement in $80.8 \%$ of cases. Most lesions were supratentorial in $92.3 \%$ of cases, and multilobar in $69.2 \%$ of cases. Abscesses were multiple in $51.7 \%$ of cases, and associated with brain herniation in $61.5 \%$ and hydrocephalus in $30.8 \%$.
With adequate treatment, $61.7 \%$ had complete resolution and $13.3 \%$ of the patients, had persistence of neurologic signs at the end of the intensive treatment period. The neurologic deficits improved by $50 \%$ by the 7 th day of treatment and even more by the 14th day. The most encountered treatment options with comparable outcomes were sulfadiazine-pyrimethamine in $61.7 \%$ of the cases, followed by Trimethoprime-sulfamethoxazole in $31.1 \%$.

\section{Conclusion}

Focal neurologic deficits of progressive onset, with or without headache and seizures, are the signs and symptoms that alert the suspicion of toxoplasma encephalitis in HIV-infected patients. Adequate treatment leads to improvement in neurologic deficits from the first week of treatment, measured with the NIHSS.

Published: 25 May 2012

doi:10.1186/1742-4690-9-S1-P145

Cite this article as: Magnerou et al:: Clinical, brain imaging and therapeutic evaluation of toxoplasma encephalitis in HIV-infected patients in Yaounde. Retrovirology 2012 9(Suppl 1):P145.

* Correspondence: melanieannick@yahoo.fr

Université des Montagnes, Douala, Cameroon

(c) 2012 Magnerou et al; licensee BioMed Central Ltd. This is an Open Access article distributed under the terms of the Creative 